\title{
DNA Sensor IFI204 Contributes to Host Defense Against Staphylococcus aureus Infection in Mice
}

\author{
Wei Chen ${ }^{1 t}$, Shui-Xing Yu ${ }^{2 t}$, Feng-Hua Zhou ${ }^{1}$, Xiao-Jing Zhang ${ }^{1}$, Wen-Ying Gao ${ }^{3}$, \\ Kun-Yu Li ${ }^{1}$, Zhen-Zhen Liu ${ }^{1}$, Wen-Yu Han ${ }^{1 *}$ and Yong-Jun Yang ${ }^{1 *}$ \\ ${ }^{1}$ Key Laboratory of Zoonosis Research, Ministry of Education, College of Veterinary Medicine, Jilin University, Changchun, \\ China, ${ }^{2}$ State Key Laboratory of Reproductive Regulation and Breeding of Grassland Livestock, School of Life Sciences, Inner \\ Mongolia University, Hohhot, China, ${ }^{3}$ Institute of Translational Medicine, The First Hospital, Jilin University, Changchun, China
}

OPEN ACCESS

Edited by:

Catarina R. Almeida, University of Aveiro, Portugal

Reviewed by:

Xiaocui He,

La Jolla Institute for Immunology (LJI), United States

Santo Landolfo,

University of Turin, Italy

*Correspondence:

Yong-Jun Yang

youngjune@jlu.edu.cn

Wen-Yu Han

hanwy@jlu.edu.cn

tThese authors have contributed equally to this work

Specialty section:

This article was submitted to

Molecular Innate Immunity,

a section of the journal

Frontiers in Immunology

Received: 31 December 2018

Accepted: 21 February 2019

Published: 18 March 2019

Citation:

Chen W, Yu S-X, Zhou F-H,

Zhang X-J, Gao W-Y, Li K-Y, LiU Z-Z, Han $W-Y$ and Yang Y-J (2019) DNA Sensor IFI204 Contributes to Host Defense Against Staphylococcus aureus Infection in Mice.

Front. Immunol. 10:474. doi: 10.3389/fimmu.2019.00474
Interferon-inducible protein (IFI204) (p204, the murine homolog of human IFI16) is known as a cytosolic DNA sensor to recognize DNA viruses and intracellular bacteria. However, little is known about its role during extracellular bacterial infection. Here we show that IFI204 is required for host defense against the infection of Staphylococcus aureus, an extracellular bacterial pathogen. IFI204 deficiency results in decreased survival, increased bacterial loads, severe organs damage, and decreased recruitment of neutrophils and macrophages. Production of several inflammatory cytokines/chemokines including IFN- $\beta$ and $\mathrm{KC}$ is markedly decreased, as well as the related STING-IRF3 and NF- $\mathrm{kB}$ pathways are impaired. However, exogenous administration of recombinant $\mathrm{KC}$ or IFN- $\beta$ is unable to rescue the susceptibility of IFI204-deficient mice, suggesting that other mechanisms rather than KC and IFN- $\beta$ account for IFI204-mediated host defense. IFI204 deficiency leads to a defect in extracellular bacterial killing in macrophages and neutrophils, although bacterial engulf, and intracellular killing activity are normal. Moreover, the defect of bactericidal activity is mediated by decreased extracellular trap formation in the absence of IFI204. Adoptively transferred WT bone marrow cells significantly protect WT and IFI204-deficient recipients against Staphylococcus infection compared with transferred IFI204-deficient bone marrow cells. Hence, this study suggests that IFI204 is essential for the host defense against Staphylococcus infection.

Keywords: Staphylococcus aureus (MRSA), IFI204, DNA sensor, STING, IFI16, innate immune, phagocytosis, extracellular trap

\section{INTRODUCTION}

The pathogen Staphylococcus aureus persistently colonizes a large proportion of the human population and is a frequent cause of skin and soft tissue infections, pneumonia, and sepsis. Despite intense research in understanding the pathogenesis and host-pathogen interaction, the mechanisms by which Staphylococcus is cleared from the host are largely unclarified, thereby impeding the development of novel strategies for control of this infection.

The innate immune system plays a key role in the early recognition and elimination of invading pathogens. Sensing bacteria through pattern recognition receptors (PRRs) enables innate immune cells to categorize microbial invaders and to initiate appropriate signaling cascades that mobilize 
defense mechanisms (1). Characterized as a DNA sensor, interferon-inducible protein 204 (IFI204) (its human ortholog IFI16) is one member of PRRs that detects cytosolic DNA for the type I IFN response (2). In response to cytosolic DNA stimulation or virus infection, IFI204/IFI16 interacts with STING to induce TBK1-dependent IFN- $\beta$ production. Several studies also reported that IFI204/IFI16 recognizes DNA viral genomes in the nucleus and activates the inflammasome pathway through ASC and caspase- 1 , leading to IL- $1 \beta$, and IL-18 production $(3,4)$.

IFI204/IFI16 is also implicated in sensing intracellular bacterial infection. Knockdown of IFI204/IFI16 by small interfering RNA significantly inhibited IFN- $\beta$ release in response to intracellular bacterial infections such as Francisella novicida (5), Listeria monocytogenes (6), Mycobacterium bovis (7). Previously, we also showed that Listeria monocytogenes-derived genomic DNA triggered programmed cell death in human trophoblasts via IFI16 (8). Obviously, cytosolic bacteria-derived dsDNA is the stimulating ligand for IFI204/IFI16-mediated immune responses.

In contrast to the extensive studies of IFI204/IFI16-mediated response to viral and intracellular bacterial infections through gene knockdown in vitro, there is little knowledge regarding the role of IFI204/IFI16 in response to extracellular bacterial infection. Here, using IFI204-deficient mice we explored the action of IFI204 in host defense against Staphylococcus, which is generally spoken as an extracellular bacteria.

We find that IFI204 protects the host against Staphylococcus infection. IFI204-deficient mice exhibit higher mortality rates, more bacterial loads, and severer organs damage compared with control mice. Although IFI204 deficiency results in a defect of IFN- $\beta$ and KC production through impairing STING-IRF3 and NF- $\kappa \mathrm{B}$ signaling, neither IFN- $\beta$ nor KC accounts for IFI204mediated host defense. IFI204 deficiency inhibits extracellular bacterial killing rather than engulf and intracellular killing activities. Interestingly, we find that the defect of bactericidal activity in the absence of IFI204 is mediated by decreased extracellular trap formation. Collectively, our results suggest that IFI204 is essential for the host defense against extracellular bacterial infection through enhancing bactericidal activity.

\section{MATERIALS AND METHODS}

\section{Mice and Cells}

IFI204-deficient mice were purchased from Nanjing Biomedical Research Institute of Nanjing University (Nanjing, China) and were subsequently backcrossed onto the C57BL/6J background for another eight generations. Heterozygous breeding pairs were used to generate wild-type (WT) mice. Bone marrow-derived macrophages (BMDMs) were isolated from mouse femurs of 810 week old mice and cultured in RPMI1640 medium containing 10\% heat-inactivated FBS, 25\% L929 cell-conditioned medium,

Abbreviations: IFI204, interferon-inducible protein 204; IFI16, interferon gamma inducible protein 16; Staphylococcus, Staphylococcus aureus; MOI, multiplicity of infection; BMDM, bone marrow-derived macrophage; PMA, phorbol 12-myristate 13-acetate; PRR, pattern recognition receptor; TLR, toll-like receptor; STING, stimulator of interferon genes; CFU, colony-forming unit; $\mathrm{H} \& \mathrm{E}$, hematoxylin and eosin; rIFN- $\beta$, recombinant IFN- $\beta$; rKC, recombinant KC.
$100 \mathrm{U} / \mathrm{mL}$ penicillin, and $100 \mathrm{U} / \mathrm{mL}$ streptomycin at $37^{\circ} \mathrm{C}$ in a humidified atmosphere containing $5 \% \mathrm{CO}_{2}$. Cells were harvested for assays at day 7 of differentiation. For isolation of elicited peritoneal macrophages (PMs), age- and sex-matched WT and IFI204-deficient mice were intraperitoneally (i.p.) injected with $1.0 \mathrm{~mL}$ of $3 \%$ sterile thioglycollate broth (Sigma-Aldrich). Four days after the injection, cells were harvested by i.p. lavage with ice-cold PBS and cultured in DMEM medium containing 10\% heat-inactivated FBS.

\section{Pulmonary and Systemic Infection}

Staphylococcus USA300 strain was grown to exponential phase in Tryptic Soy Broth (TSB) at $37^{\circ}$ C. Six to eight weeks old sexmatched mice were intranasally or intravenously infected with $1 \times 10^{8}$ or $2 \times 10^{8}$ colony-forming unit (CFU) Staphylococcus USA300 diluted in PBS in a total volume of 20 or 200 $\mu \mathrm{L}$. Bronchoalveolar lavage fluid (BALF) was obtained by lavaging the lung with $1 \mathrm{~mL}$ PBS containing $100 \mu \mathrm{g} / \mathrm{mL}$ soybean trypsin inhibitor.

\section{Bacterial Burden and Cytokine Measurements}

Aseptically excised tissues were homogenized. Serial dilutions of tissue homogenates were plated on agar plates and bacterial loads (CFU/g) were determined by colony counting after overnight incubation. The tissues were homogenized mechanically in cold PBS (at a ratio of $6 \mathrm{~mL}$ per gram tissue) containing complete protease inhibitor cocktail and 1\% Triton X-100. Tissue homogenates were then centrifuged at $12,000 \mathrm{rpm}$ for $20 \mathrm{~min}$. The supernatants were collected. Concentrations of various cytokines/chemokines in BALF, tissue homogenates or cell culture supernatants were determined by ELISA using antibody pairs from $\mathrm{R} \& \mathrm{D}$ according to manufacturer's manual.

\section{Tissue Histology and Immunostaining}

Tissue samples of lung and kidney were fixed in buffered formalin solution (4\%) and embedded in paraffin. Tissue sections $(5 \mu \mathrm{m})$ were deparaffinized, rehydrated, and stained with hematoxylineosin. For immunohistochemistry, sections were subjected to an antigen retrieval step, followed by blocking for $1 \mathrm{~h}$ at room temperature, then stained with IFI204 (Lifespan), Ly-6G/Ly-6c (BioLegend), and F4/80 (BioLegend) antibodies. Subsequently, specific staining was detected using the UltraSensitive S-P Kit and DAB Detection Kit (Maixin-Bio) according to the manufacturer's directions. For immunofluorescence, cells were stained with phospho-IRF3 (Santa Cruz), IFI204 (Lifespan), STING (Proteintech) primary antibodies, and Alexa Fluor ${ }^{\circledR}$ 488-conjugated secondary antibodies (Invitrogen). Kidney cell apoptosis was analyzed by TUNEL staining using a commercial kit (KeyGEN Biotech). DAPI ( $1 \mu \mathrm{g} / \mathrm{mL})$ was used to stain nuclei.

\section{Quantitative PCR}

RNA was isolated using TRI reagent (Sigma-Aldrich) and converted into cDNA. Subsequently, Real-Time PCR assays were performed using SYBR Green (Roche) on ABI Prism 7500 sequence detection system (Applied Biosystems). Gene expression levels were calculated using the $2^{-\Delta \mathrm{Ct}}$ method. The 
following primers were used: IFN- $\beta$ sense $5^{\prime}$-ACT GCC TTT GCC ATC CAA GA-3', antisense 5'-CAC TGT CTG CTG GTG GAG TT-3'. KC sense $5^{\prime}$-ACC CTG AAG CTC CCT TGG TT$3^{\prime}$, KC antisense $5^{\prime}$-AGA AGC CAG CGT TCA CCA GA-3'. IFI204 sense $5^{\prime}$-CAG GGA AAA TGG AAG TGG TG-3', IFI204 antisense 5'-CAG AGA GGT TCT CCC GAC TG-3'. GAPDH sense $5^{\prime}$-CAC CCC AGC AAG GAC ACT GAG CAA G-3',

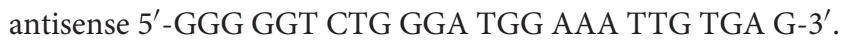

\section{Western Blotting}

The cells or tissues were homogenized in lysis buffer solution ( $1 \%$ Triton X-100, 50 mM Tris- $\mathrm{HCl}, 150$ mM NaCl, 0.1 mM Na 3 VO4) supplemented with complete protease inhibitor cocktail (SigmaAldrich). The lysates were separated by SDS-PAGE, and transferred onto PVDF membrane. The membranes were blotted with antibodies against IFI204 (Lifespan), phospho-IRF3 (Santa Cruz), phospho-IкB $\alpha$ (Cell Signaling Technology), ІкB $\alpha$ (Cell Signaling), phospho-NF-кB P65 (Cell Signaling), IRF3 (Abcam), IFI204 (Lifespan), STING (Proteintech), GAPDH (Proteintech), or $\beta$-Tubulin (Sungene Biotech).

\section{Administration of Recombinant KC and IFN- $\beta$}

IFI204 ${ }^{-/-}$mice were i.p. injected recombinant $\mathrm{KC}$ or IFN$\beta$ (MBL International) at a dose of $1.0 \mu \mathrm{g}$ per mouse in $100 \mu \mathrm{L}$ PBS on Day -1 and Day 0. The mice were infected intranasally with $1 \times 10^{8} \mathrm{CFU}$ of Staphylococcus on Day 0 . Aseptically excised tissues were homogenized at $24 \mathrm{hpi}$. Serial dilutions of tissue homogenates were plated on agar plates and bacterial loads $(\mathrm{CFU} / \mathrm{g})$ were determined by colony counting after overnight incubation.

\section{In vivo Neutralization of IFNAR1}

Mice were i.p. inoculated with $2.5 \mathrm{mg}$ anti-mouse IFNAR1 neutralizing mAb (clone MAR1-5A3, BioXcell) or $2.5 \mathrm{mg} \mathrm{IgG}$ isotype control (Clone MOPC-21, BioXcell). Twenty-four hours later, the mice were anesthetized with pentobarbital sodium and i.v. challenged with $2 \times 10^{8} \mathrm{CFU}$ of Staphylococcus suspended in $200 \mu \mathrm{L}$ PBS. Mortality was monitored.

\section{Internalization Assay}

To determine whether IFI204 impact the bacterial internalization of Staphylococcus, $2.5 \times 10^{9} \mathrm{CFU} / \mathrm{mL}$ live or heat-killed bacteria were incubated with $0.15 \mathrm{mg} / \mathrm{mL}$ fluorescein isothiocyanate (FITC) in the dark for $30 \mathrm{~min}$ at RT. The bacteria were washed 3 times with PBS to remove unbound FITC. WT or IFI204 ${ }^{-/-}$ BMDM were treated with FITC-labeled live or killed bacteria $(\mathrm{MOI}=5)$ for indicating times. The extracellular fluorescence was quenched using $0.2 \%$ trypan blue. The mean fluorescence intensity (MFI) of the FITC-positive cells were determined by flow cytometric analyses.

\section{Intracellular and Extracellular Killing Assays}

To determine whether IFI204 impact the intracellular bacterial killing capacity of macrophages, WT or IFI $204^{-/-}$BMDM were incubated with Staphylococcus $(\mathrm{MOI}=5)$ for $1 \mathrm{~h}$, and then nonengulfed bacteria were killed with $100 \mu \mathrm{g} / \mathrm{mL}$ gentamicin for $1 \mathrm{~h}$. The cells were lysed with $0.1 \%$ Triton X-100 and intracellular bacterial were enumerated by serial dilution and plating on TSB agar plates. To determine whether IFI204 impact the extracellular bacterial killing capacity of macrophages or neutrophils, WT and IFI204 ${ }^{-/-}$BMDM or neutrophil were incubated with Staphylococcus $(\mathrm{MOI}=5)$ for $6 \mathrm{~h}$, the supernatant was collected and centrifuged at $600 \times \mathrm{g}$ for $5 \mathrm{~min}$. The pelleted bacteria were resuspended in PBS and plated on TSB agar plates to enumerate the extracellular bacteria.

\section{ETs Formation Assays}

Bone marrow macrophages or neutrophils were isolated from WT or IFI $204^{-/-}$mice. The cells were seeded on $12-\mathrm{mm}$ $0.01 \%$ poly-l-lysine-coated coverslips in 24 well-plates and were challenged with bacteria (MOI $=50)$. Cells were fixed with $4 \%$ paraformaldehyde and then stained with SYTOX Orange $(5 \mu \mathrm{M})$ and Hochest $33342(2 \mu \mathrm{M})$. ETs were visualized on a fluorescence microscope and images were taken. Macrophages were stimulated with bacteria $(\mathrm{MOI}=50)$ and PMA $(100 \mathrm{nM})$. SYTOX Orange was added after $6 \mathrm{~h}$ and fluorescence was measured by spectrofluorometry.

\section{Adoptive Transfer of Bone Marrow Cells}

Six-eight week old mice were lethally irradiated with $10 \mathrm{~Gy}$ of $\gamma$ radiation at a rate of $1.5 \mathrm{~Gy} / \mathrm{min}$ in a ${ }^{137} \mathrm{Cs}$ irradiator. Within $24 \mathrm{~h}$ of irradiation, mice received an intravenous injection of 8 $\times 10^{6}$ bone marrow cells harvested from the femurs and tibias of WT or IFI $204^{-/-}$mice. Mice were allowed to recover at least 7 weeks before being used for experiments. Efficient reconstitution by donor bone marrow cells was confirmed by PCR for the IFI204 gene in splenocytes (Figure 8G).

\section{MPO Assay}

Lung tissues were homogenized in $0.5 \%$ cetyltrimethylammonium chloride (4 $\mu \mathrm{L} / \mathrm{mg}$ lung). The cleared supernatant was used for MPO assay to determine the infiltration of neutrophils. Briefly, samples in duplicate (75 $\mu \mathrm{L})$ were mixed with equal volumes of the substrate $\left(3,3^{\prime}, 5,5^{\prime}\right.$ tetramethyl-benzidine dihydrochloride, $3 \mathrm{mmol} / \mathrm{L}$; resorcinol, $120 \mu \mathrm{mol} / \mathrm{L}$; and $\mathrm{H}_{2} \mathrm{O}_{2}, 2.2 \mathrm{mmol} / \mathrm{L}$ ) for $2 \mathrm{~min}$. The reaction was stopped by adding $150 \mu \mathrm{L}$ of $2 \mathrm{~mol} / \mathrm{L} \mathrm{H}_{2} \mathrm{SO}_{4}$. The OD was measured at $450 \mathrm{~nm}$.

\section{Statistical Analysis}

Date are represented as mean \pm SEM. Differences between mean values of normally distributed data were assessed with one-way ANOVA (Dunnett's $t$-test) and two-tailed Student's $t$ test. Log-rank test was used for statistical analysis of animal mortality. ${ }^{*} p<0.05$; ${ }^{* *} p<0.01$ compared with control group. Statistical analysis was performed using Prism (GraphPad Software, La Jolla, CA). 


\section{RESULTS}

\section{IFI204 Deficiency Attenuates Bacterial Clearance Following Staphylococcus Pulmonary Infection}

Using Staphylococcus lung infection model, we initially explored the possible involvement of IFI204 in the host response to Staphylococcus infection. WT (wild-type) and IFI204-/(IFI204-deficient) mice were intranasally infected with $1 \times 10^{8}$ CFU (colony-forming units) of Staphylococcus. Bacterial burdens were assessed in BALF (bronchoalveolar lavage fluid), blood and various tissues at 16 hpi by CFU counting. Significantly more bacteria were detected in the lungs, BALF and blood of IFI $204^{-/-}$mice compared with WT mice (Figures 1A-F). In line with this, histopathological examination of lung tissues $48 \mathrm{~h}$ after Staphylococcus challenge showed that there were more severe injury in IFI204 $4^{-/}$mice (Figure 1G). To further characterize the role of IFI204 in host defense against Staphylococcus, WT and IFI204 $4^{-/}$mice were intranasally infected with $2 \times 10^{8}$ CFU of Staphylococcus and animal mortality was then monitored. IFI204 ${ }^{-/-}$mice demonstrated a slight lower survival rate than their WT counterparts within $48 \mathrm{hpi}$, but the difference was not significant (Figure 1H). Thus, these data suggest that IFI204 is involved in host defense against Staphylococcus pulmonary infection.

\section{IFI204 Deficiency Decreased Inflammatory Cells Recruitment and Cytokines/Chemokines Production}

To identify the potential mechanisms that contribute to higher bacterial loads in IFI204 ${ }^{-/}$mice, we examined lung recruitment of neutrophil and macrophage because these cells are critical for the clearance of bacteria. Histological study showed less neutrophils and macrophages accumulation in the airways of IFI204 $/-$ mice at 24 hpi compared with WT mice (Figures 2A,B). In mice receiving the shamoperation, no significant cellular influx was observed in the lung of both genotype mice. To determine if the decreased inflammatory cells influx is dependent on inferior production of cytokines/chemokines following Staphylococcus infection, we measured the expression of cytokines (IL-6, IL-1 $\beta$, and IFN$\beta$ ) and chemokines (KC/CXCL1, CXCL2, and CXCL10) in lung homogenates, BALF or blood at $24 \mathrm{~h}$ after Staphylococcus challenge (Figures 2C-N). Bacterial challenge dramatically induced the release of these cytokines/chemokines from WT mice. However, the production of these cytokines/chemokines in IFI $204^{-/-}$mice were attenuated compared with WT mice. Thus, IFI204 deficiency results in impaired immune responses to Staphylococcus pulmonary infection.

\section{IFI204 Deficiency Attenuates Bacterial Clearance Following Staphylococcus Systemic Infection}

To further characterize the role of IFI204 in pulmonary defense against Staphylococcus, the expression of IFI204 in the lung sections was investigated by immunohistochemical staining.
Our results showed that IFI204 staining was mainly detected in the recruited inflammatory cells of the infected lungs (Figure 3A). Next, we asked if IFI204 regulated host defense against Staphylococcus systemic infection. WT and IFI204-/mice were i.v. infected with $1 \times 10^{8} \mathrm{CFU}$ of Staphylococcus. Animal mortality was then monitored for $10 \mathrm{~d}$. IFI204-/- mice demonstrated a significantly lower survival rate than their WT counterparts (Figure 3B). Kidney injury was more severe in IFI204 ${ }^{-/-}$mice compared with WT mice as determined by H\&E and TUNEL histology (Figures 3C,D). To determine whether a defect in bacterial clearance contribute to the death of IFI204deficient mice, bacterial numbers in blood, spleen, kidney, and liver were enumerated at $24 \mathrm{hpi}$. As compared with WT mice, IFI204-deficient mice had higher bacterial burdens in blood and kidney (Figures 3E-H), indicating that IFI204 deficiency facilitates bacterial growth and dissemination.

\section{IFI204 Promotes Cytokines/Chemokines Production in Macrophages}

Next, we set out to characterize the inflammatory response in WT and IFI204-deficient macrophages in vitro. Bone marrow-derived macrophages (BMDM) derived from WT mice were infected with Staphylococcus at a multiplicity of infection (MOI) of 1:50. IFI204 mRNA and protein levels were significantly up-regulated by bacteria challenge (Figures 4A,B). We further examined IFI204 expression by immunofluorescence. IFI204 was detected in the nuclear of WT cells and absent from IFI204-deficient cells (Figure 4C). We next asked if IFI204 deficiency impair cytokines production in macrophages. Staphylococcus dramatically induced IFN- $\beta$ and KC mRNA and protein expression in WT cells (Figures 4D-G). However, the levels of IFN- $\beta$ and $\mathrm{KC}$ were significantly reduced in IFI204-deficient macrophages. IFI204 is characterized as a DNA sensor. A similar effect of IFI204 on $\mathrm{KC}$ and IFN- $\beta$ production triggered by Staphylococcus-derived genomic DNA was found (Figures 4H,I). Collectively, these results provided in vitro evidence that IFI204 mediates cytokine secretion, which was consistent with the in vivo data.

\section{IFI204 Deficiency Suppresses STING-IRF3 and NF- $\kappa$ B Signaling}

To illustrate the signaling mechanism that results in cytokine decrease upon Staphylococcus infection in the absence of IFI204, IRF3 activation was assessed by Western blotting. The data showed that IRF3 was hypophosphorylated in IFI204-deficient BMDMs and peritoneal macophages compared with the control cells (Figure 5A). To further dissect the pathway, we analyzed STING, which plays a pivotal role in DNA-triggered induction of IFN- $\beta$ (9). A significant decreased induction of STING was seen in IFI204-deficient macrophages (Figure 5A). The defect activation of STING and IRF3 were confirmed by immunofluorescence assay (Figure 5B). IFI204 deficiency also inhibited bacterial genomic DNA-triggered STING and IRF3 activation (Figure 5C). Moreover, NF- $\kappa \mathrm{B}$ signaling was largely impaired in the absence of IFI204, showed by the reduced phosphorylation levels of p65 and ІкBa in the treated IFI204deficient macrophages (Figure 5D). Consistently, the lung tissues 

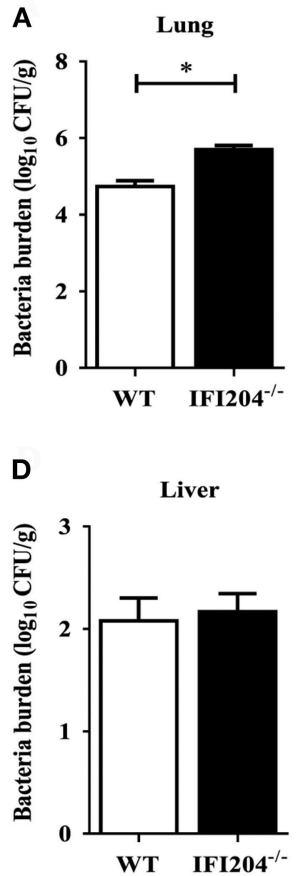

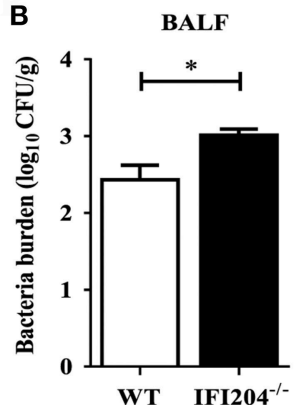

E

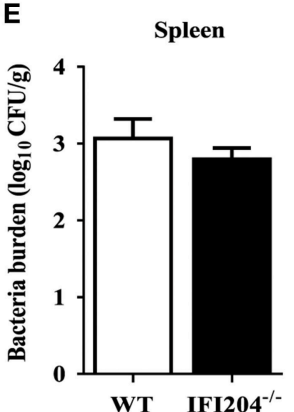

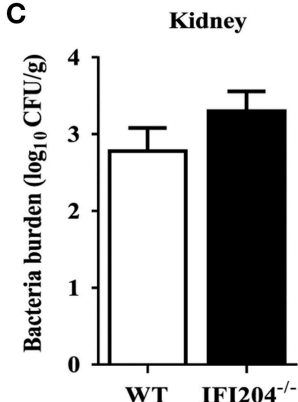

$\mathbf{F}$

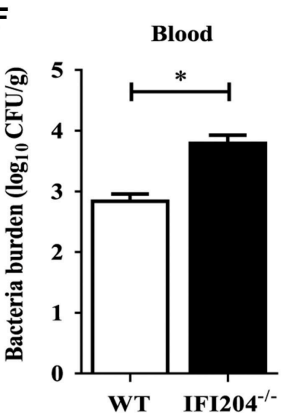

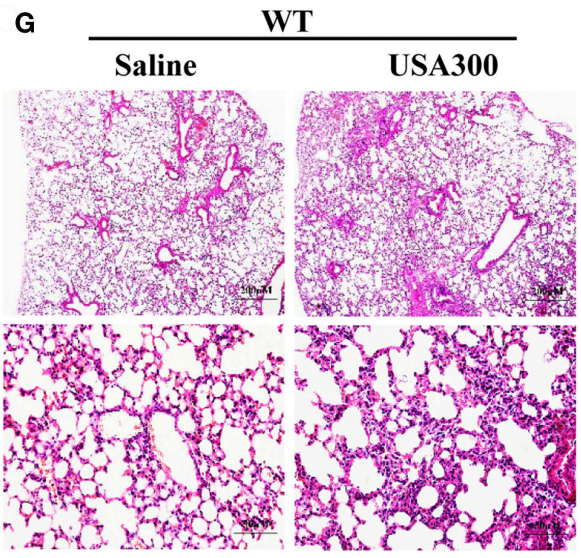

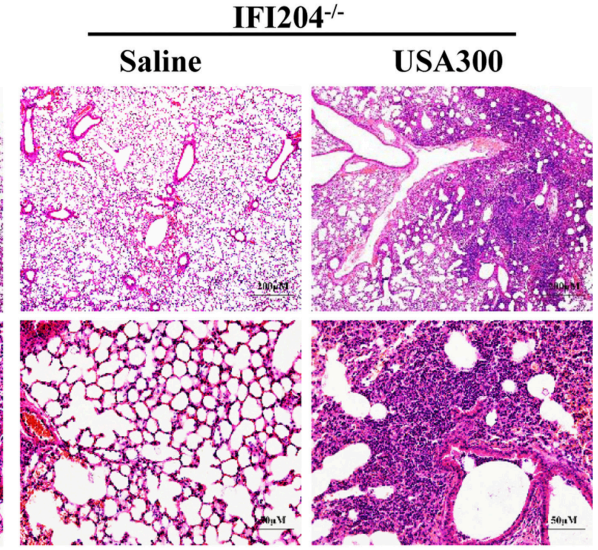

H

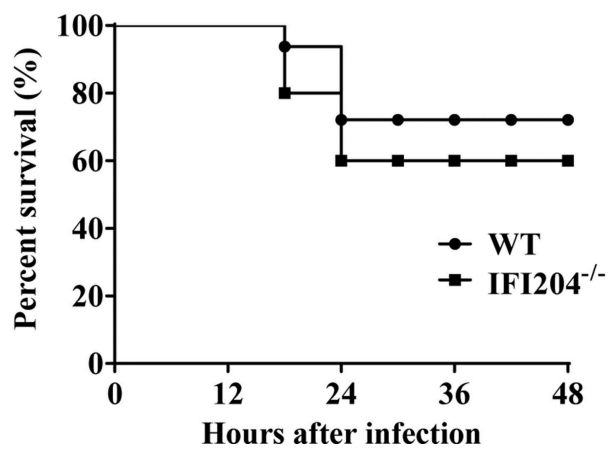

FIGURE 1 | Interferon-inducible protein 204 (IFI204)-deficient mice display increased susceptibility to Staphylococcus pulmonary infection. (A-F) Age- and sex-matched WT $(n=8)$ and IFI204 $/-(n=10)$ mice were infected intranasally with $1 \times 10^{8}$ CFU of Staphylococcus. Homogenized tissues, BALF and blood were subjected to plating serial dilution for bacterial loads at 16 hpi. All data are shown as mean \pm SEM. Student's $t$-test was performed. ${ }^{*} p<0.05$. (G) Hematoxylin-eosin staining of lung tissues collected from WT and IFI204-/- $(n=5$ each group) mice at 48 hpi. Magnification $40 \times 0$ or $200 \times$. (H) WT and IFI204-/- mice were inoculated intranasally with $2 \times 10^{8} \mathrm{CFU}$ of Staphylococcus $(n=15)$ or PBS $(n=13)$. The animals were monitored every $6 \mathrm{~h}$ up to $48 \mathrm{~h}$ for survival. 

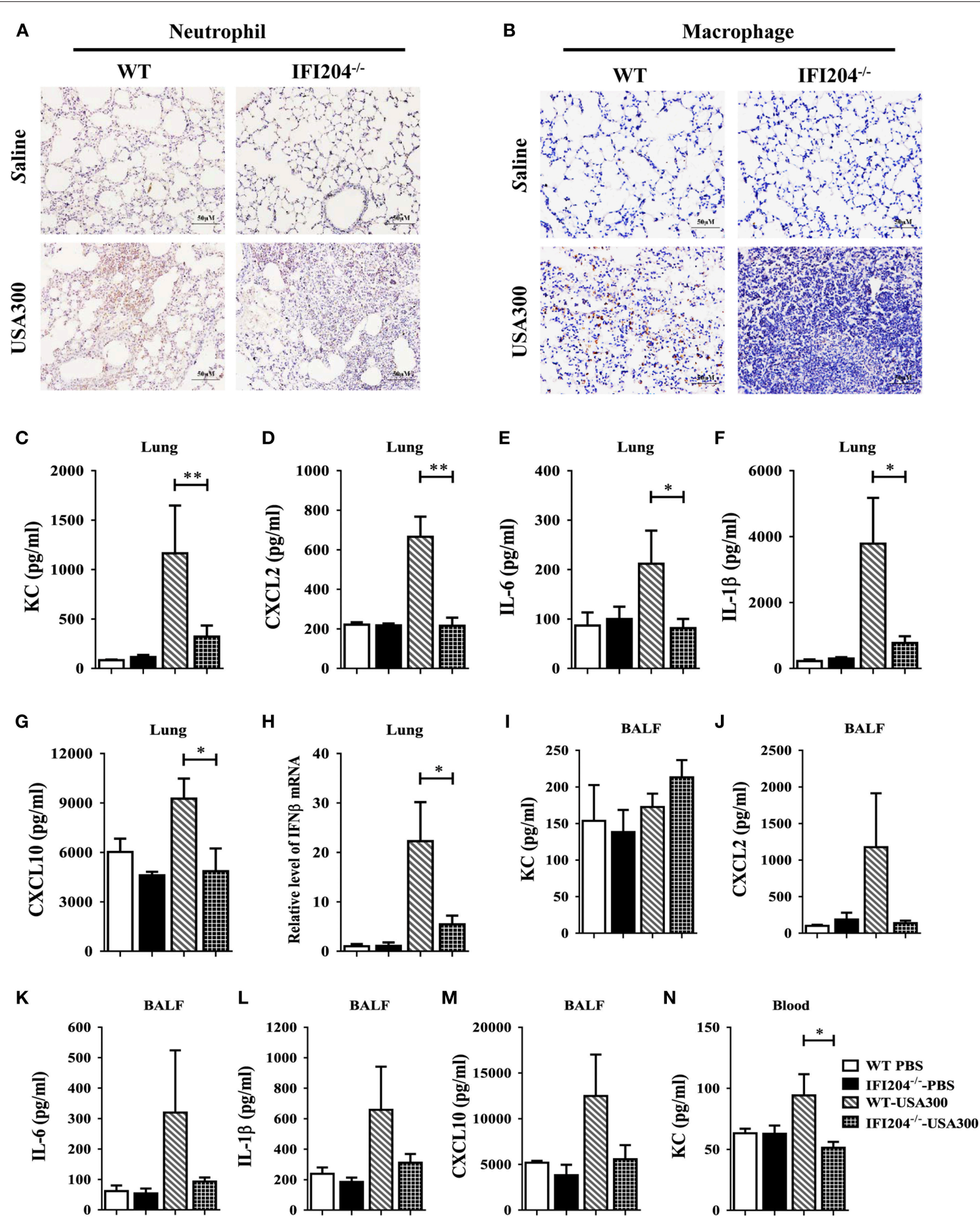

FIGURE 2 | IFI204 is required for elevated inflammatory cells recruitment and cytokines/chemokines production after Staphylococcus pulmonary infection. WT and $\mathrm{IFI} 204^{-/-}$mice ( $n=10$ each group) were infected intranasally with $1 \times 10^{8} \mathrm{CFU}$ of Staphylococcus for $24 \mathrm{~h}$. Representative immunohistochemical staining of (A) Gr-1 (a neutrophil marker) and (B) F4/80 (a macrophagocyte marker) were performed in the lung sections. (C-N) Levels of KC, CXCL2, IL-6, IL-1 $\beta$, CXCL10, and IFN- $\beta$ in lung, BALF or blood were determined. All data are shown as mean \pm SEM. Student's $t$-test was performed. ${ }^{*} p<0.05 ;{ }^{* *} p<0.01$.

of IFI204-deficient mice challenged with bacteria showed a similar trend in significantly reduced STING-IRF3 and NF-кB activation compared with the controls (Figure 5E). Collectively, these results suggested that upon Staphylococcus challenge, IFI204 deficiency impaired the Sting-IRF3 and NF-кB pathways in vitro and in vivo. 

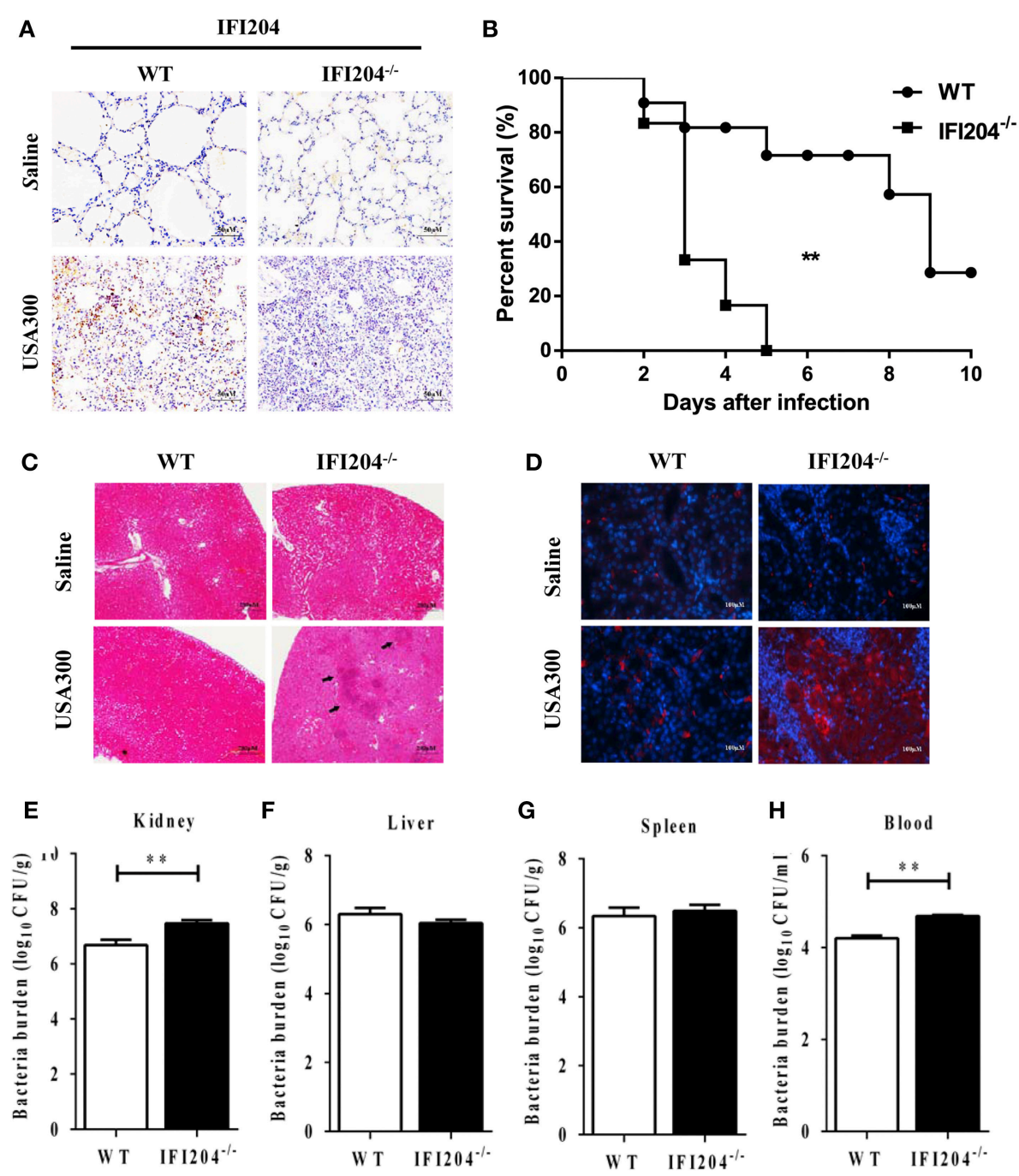

FIGURE 3 | IFI204-deficient mice displayed increased susceptibility to Staphylococcus systemic infection. (A) Lung sections were stained with anti-IFI204. (B) WT $(n=15)$ and IFI204 $-/-(n=13)$ mice were infected $i . v$ with $1 \times 10^{8}$ CFU of Staphylococcus. The animals were monitored daily up to 10 days for survival. The Kaplan-Meier and log-rank methods were used to analyze survival rates. (C,D) Kidney tissues were collected from WT and IFI204-/- mice at 48 hpi $(n=5$ each group). Kidney injury was assessed by hematoxylin-eosin staining (C) and terminal deoxynucleotidyl transferase dUTP nick end labeling (TUNEL) histology (D). Representative results are depicted. (E-H) Bacterial loads in kidney, liver, spleen, and blood of WT $(n=8)$ and IFI204-/- $(n=10)$ at 20 hpi were determined. All data are shown as mean \pm SEM. Student's $t$-test was performed. ${ }^{* *} p<0.01$.

\section{Neither KC Nor IFN- $\beta$ Contributes to IFI204-Mediated Host Defense}

Because cytokines generation and related proinflammatory signaling activation markedly attenuated in the absence of IFI204, we next examine whether exogenous administration of recombinant cytokines is able to rescue the susceptibility to infection in IFI204-deficient mice. IFI204-deficient mice were treated prophylactically (day -1 and day 0 of infection) with rKC or IFN- $\beta$ and then infected with Staphylococcus. However, bacterial burdens in the lung tissue at $6 \mathrm{hpi}$ were not inhibited by both recombinant proteins (Figure 6A). We further examined the effect of recombinant proteins at 24 hpi. A similar result was got (Figures 6B,C). Indeed, blockade of IFN signaling using
anti-IFNAR1 MAb significantly decreased the mortality induced by Staphylococcus systemic infection (Figure 6D). Therefore, KC and IFN- $\beta$ was not necessary for the protective effects of IFI204 during bacterial infection.

\section{IFI204 Deficiency Results in the Defect of Extracellular Trap-Mediated Bacteria Killing}

Phagocytosis is a critical host defense mechanism used by macrophages. IFI204-deficient mice have elevated numbers of bacteria present in infected tissue, suggesting that these phagocytes are unable to effectively control bacterial multiplication in the absence of IFI204. We further evaluated 

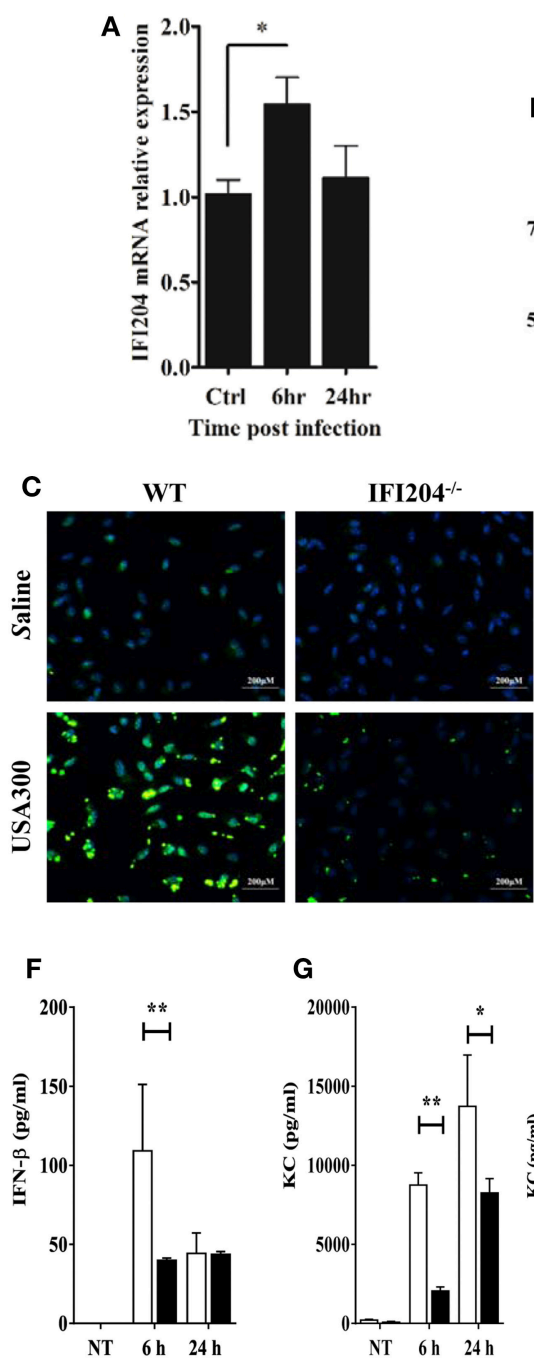

B
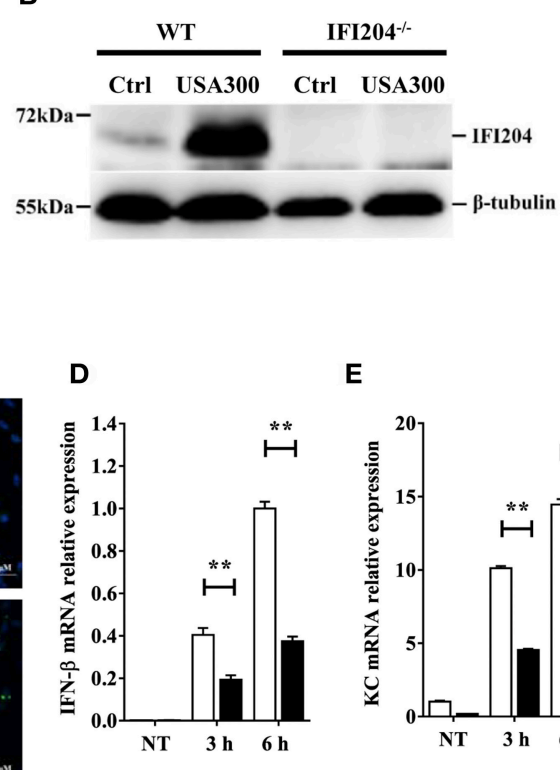

E
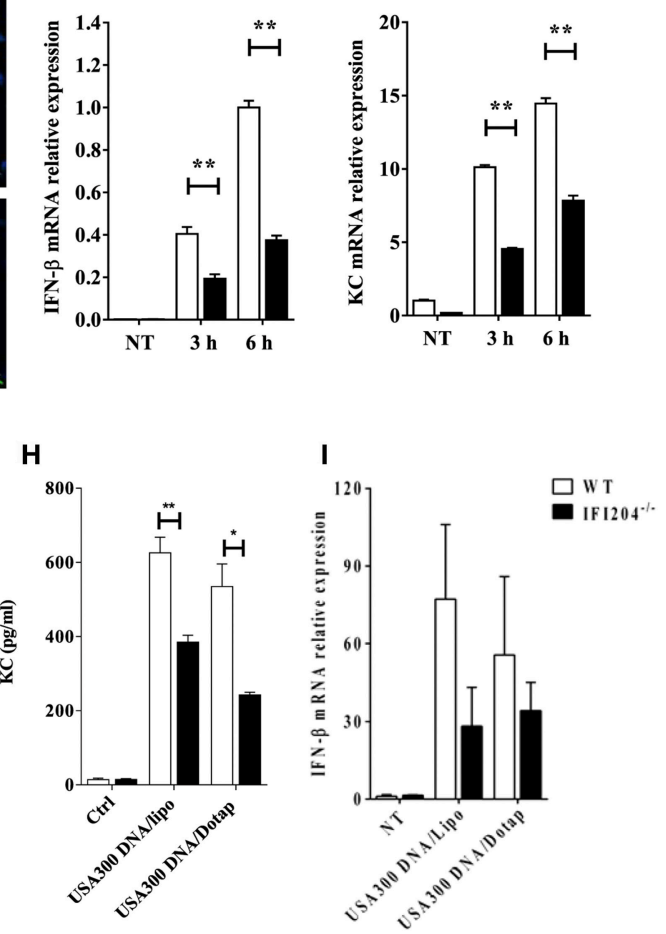

FIGURE 4 | IFI204 is upregulated and promotes proinflammatory cytokines production in BMDM following Staphyloccoccus challenge. WT and IFI204-/- BMDM were untreated or exposed to Staphylococcus at a MOI of 1:50 for indicated time. (A) IFI204 mRNA levels were measured by qRT-PCR. IFI204 protein in cells at 24 hpi was measured by Western blotting (B) and immunofluorescence microscopy (C). Shown are representative images from two independent experiments.

(D-G) Protein and/or mRNA levels of IFN- $\beta$ and $\mathrm{KC}$ in BMDM were examined at the indicated time after infection. (H,I) WT and IFI204-/- BMDM were transfected with Staphylococcus-derived genomic DNA using Lipofectamine 2000 or DOTAP. KC and IFN- $\beta$ levels were quantified by ELISA or qRT-PCR. Data shown is representative of at least three independent experiments. All data are shown as mean $\pm \mathrm{SEM}$. Student's $t$-test was performed. ${ }^{\star} p<0.05$; ${ }^{* *} p<0.01$.

the bacterial killing capacity of IFI204-deficient macrophages in vitro. Our results showed that IFI204-deficient macrophages internalized similar numbers of FITC-labeled live or heat-killed bacteria compared with WT macrophage (Figures 7A,B). Moreover, the gentamicin protection assay showed that the number of recovered viable bacteria was comparable in macrophages from both genotypes, indicating IFI204 has no effect on intracellular bacterial killing (Figure 7C). Generally speaking, Staphylococcus are extracellular bacteria that are eventually killed by phagocytes via multiple mechanisms besides phagocytosis. We further examined whether IFI204 deficiency impair extracellular killing capacity by enumerating bacteria in supernatants at $6 \mathrm{hpi}$. The results showed that IFI204 deficiency inhibited the extracellular killing capacity of macrophage (Figure 7D). Extracellular trap (ET) provides an extracellular site for microbial killing in the innate immune defense. To investigate the effect of IFI204 deficiency on ET formation, we stained macrophages with SYTOX Orange, a non-permeable dye that stains nucleic acid, a primary component of ET. Interestingly, MET formation was markedly decreased in IFI204-deficient macrophage vs. WT macrophages (Figure 7E). To quantify MET formation, we analyzed extracellular DNA content in the supernatants. A reduction of extracellular DNA was seen in IFI2014-deficient macrophages compared with WT 

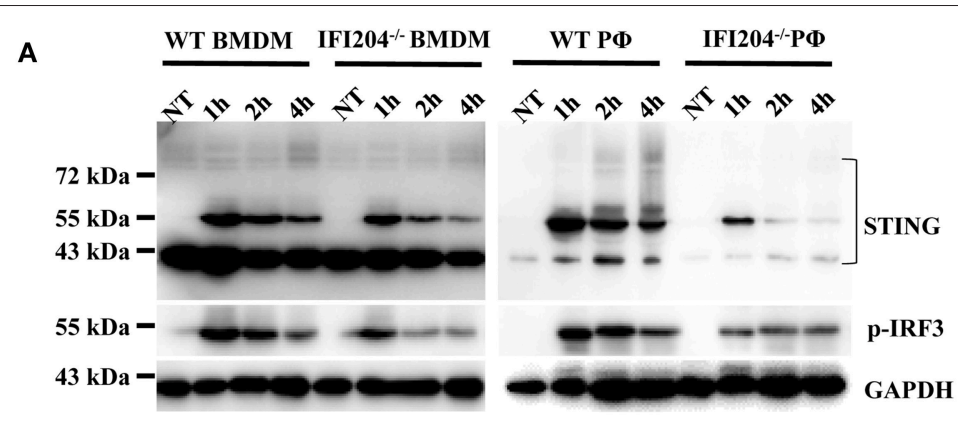

B
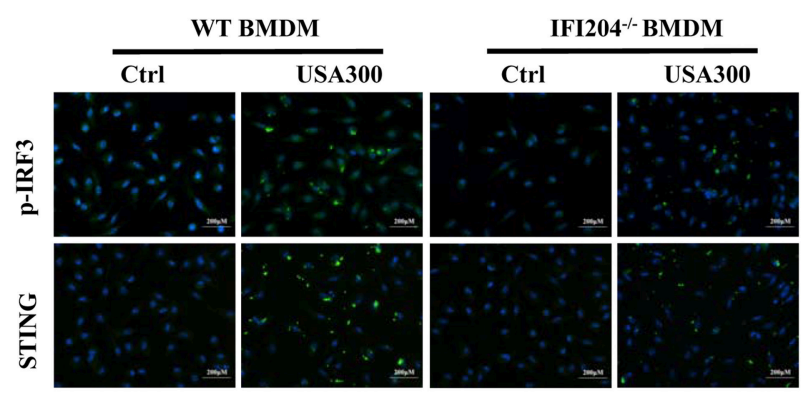

C

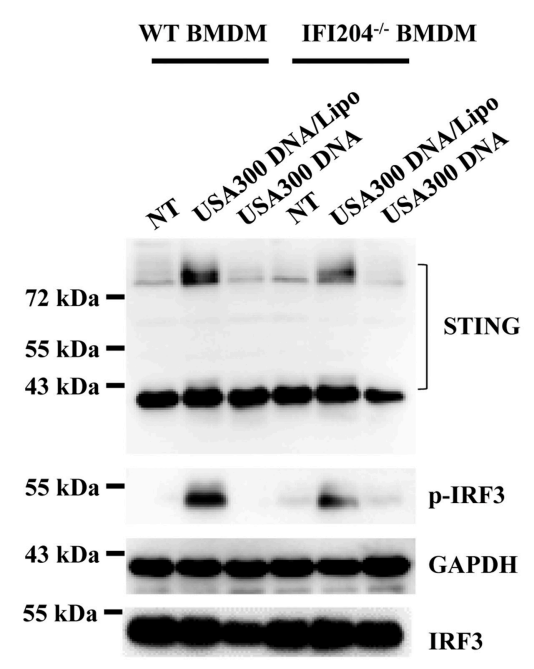

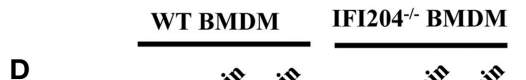

D
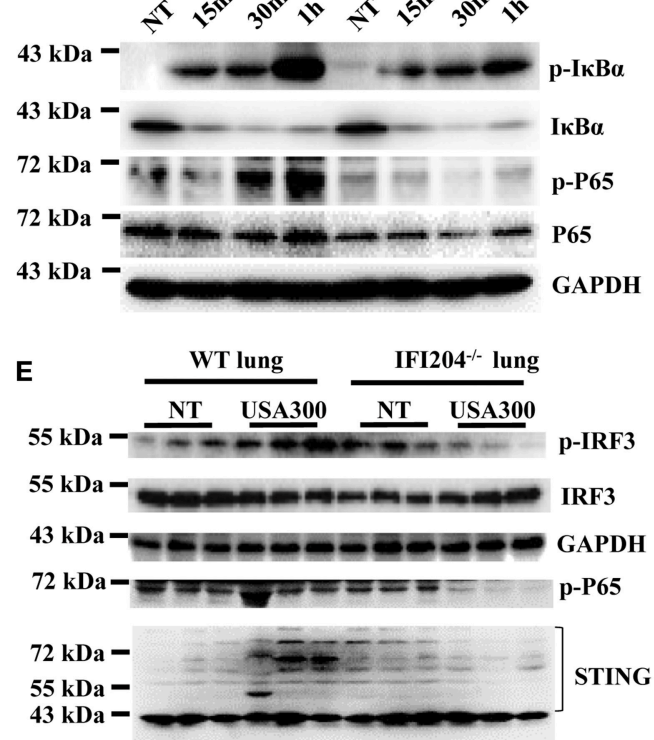

FIGURE 5 | IFI204 deficiency suppresses Staphylococcus-induced activation of STING-IRF3 and NF-кB signaling. (A) WT and IFI204-deficient BMDM and peritoneal macrophages were untreated (NT) or exposed to Staphylococcus for the indicated times. The cell lysates were examined for expression levels of STING and phospho-IRF3 by Western blotting. The GAPDH served as a loading control. (B) WT and IFI204-deficient BMDM were exposed to Staphylococcus for $1 \mathrm{~h}$. STING and phospho-IRF3 were analyzed by immunofluorescence. (C) WT and IFI204-deficient BMDM were incubated with USA300 DNA with or without Lipofectamine 2000 for $1 \mathrm{~h}$. STING and phospho-IRF3 were examined by Western blotting. (D) WT and IFI204-deficient BMDM were exposed to Staphylococcus for the indicated times. Phospho-IкB $\alpha$, IкB $\alpha$, phospho-P65, P65, and GAPDH were examined by Western blotting. (E) WT and IFI204-/- mice were infected intranasally with $1 \times 10^{8}$ CFU of Staphylococcus. Lung tissues were collected and homogenized at $24 \mathrm{~h}$ postinfection, and then immunoblotting for Sting and phospho-IRF3, IRF3, GAPDH, P65, and STING.

cells (Figure 7F). Moreover, IFI204 deficiency impaired PMAinduced extracellular DNA release. Because an initial description of ET appeared in neutrophil, another type of phagocyte that play important roles in host's defense against infection, we further examined if there is a defect of ET formation in IFI204deficient neutrophils. A similar defect of NET formation was observed in bacteria-infected IFI204-deficient neutrophils vs. WT neutrophils (Figure 7G). Correspondingly, IFI204-deficient 

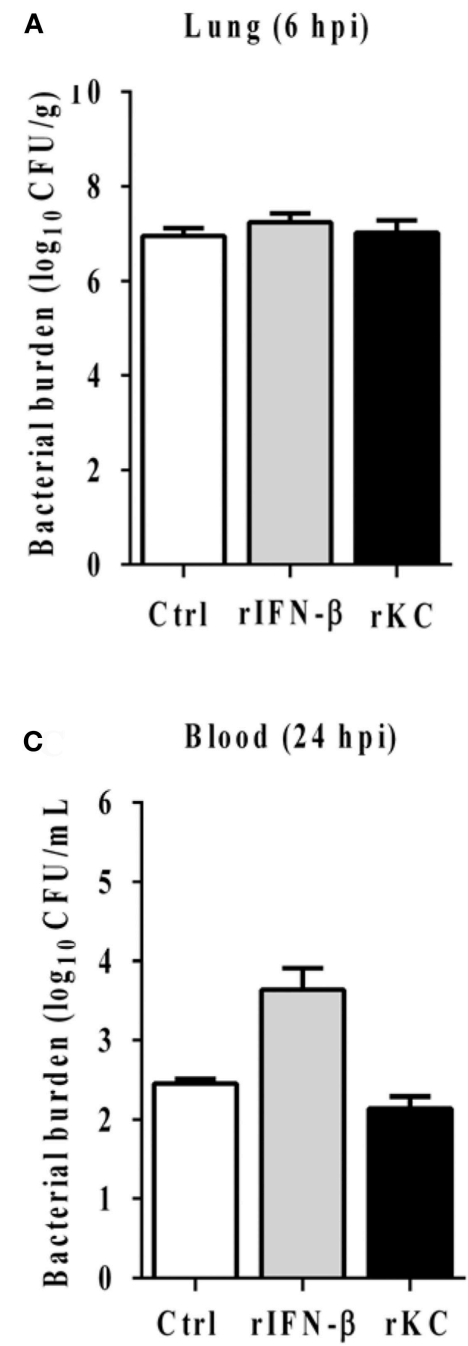

B

Lung (24 h pi)

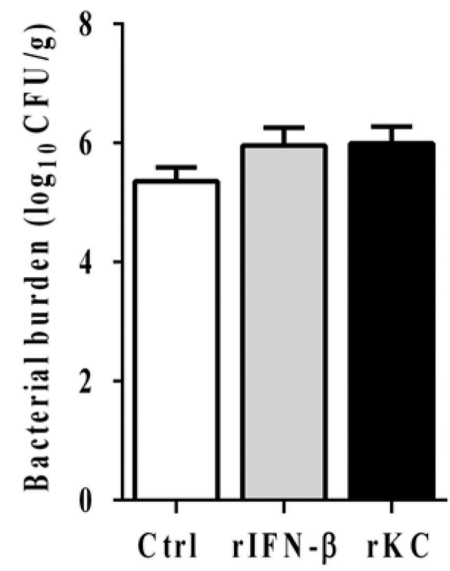

FIGURE 6 | IFN- $\beta$ and KC are dispensable for IFI204-mediated host defense. IFI204-/- mice were i.p. injected recombinant KC or IFN- $\beta$ ( $n=10$ each group) at a dose of $1.0 \mu \mathrm{g}$ per mouse in $100 \mu \mathrm{L}$ PBS on Day -1 and Day 0. The mice were infected intranasally with $1 \times 10^{8}$ CFU of Staphylococcus on Day 0 . (A,B) Homogenized lung tissues were subjected to plating serial dilution for bacterial loads at 6 hpi or 24 hpi. (C) Blood were subjected to plating serial dilution for bacterial loads at $24 \mathrm{hpi}$. All data are shown as mean \pm SEM. Student's $t$-test was performed. (D) The mice were i.p. injected with 2.5 mg anti-mouse IFNAR1 neutralizing $\mathrm{mAb}$ or $2.5 \mathrm{mg}$ lgG isotype control ( $n=8$ each group), $24 \mathrm{~h}$ later, mice were i.v. challenged with $2 \times 10^{8} \mathrm{CFU}$ of Staphylococcus. The animals were monitored daily for survival. ${ }^{\star \star \star} p<0.005$.

neutrophils were incapable of killing extracellular bacteria compared with WT neutrophils (Figure 7H). Hence, these data suggested that IFI204 deficiency leads to a defect in extracellular bacterial killing by impairing ET formation in phagocytes.

\section{Bone Marrow Transplantation Restore Bacteria Killing in IFI204-Deficient Mice}

To further substantiate the pivotal role of IFI204 in enhancing extracellular bacteria killing, we further examined if transplantation of WT bone marrow (BM) rescue bacterial killing defect in IFI204-deficient mice. WT or IFI204-deficient recipient mice were lethally irradiated and injected with BM cells from WT or IFI204-deficient donors. Eight weeks after transplantation, those mice were inoculated with Staphylococcus, and bacterial burdens in the lung and blood were determined. Similar to WT recipient mice that received WT BM, IFI204-deficient recipient mice that received $\mathrm{WT} B \mathrm{BM}$ had less bacterial burden (Figures 8A,B). Conversely, WT recipient mice that received IFI204-deficient BM had more bacterial burden in lung tissue, identical to that observed in IFI204-deficien recipient mice that received IFI204-deficient BM. The similar pattern was observed in the activity of MPO (Figure 8C), one granule enzyme which plays an important role in neutrophil antimicrobial responses and is required for neutrophil extracellular trap formation (10). The proinflammatory cytokines (KC and IL-1 $\beta$ ) in lung showed slight similar patterns (Figures 8D-F). Depletion of circulating cells and reconstitution with donor cells was comfirmed (Figure 8G). Together, the results indicate that the protective effect of IFI204 against Staphylococcus infection 

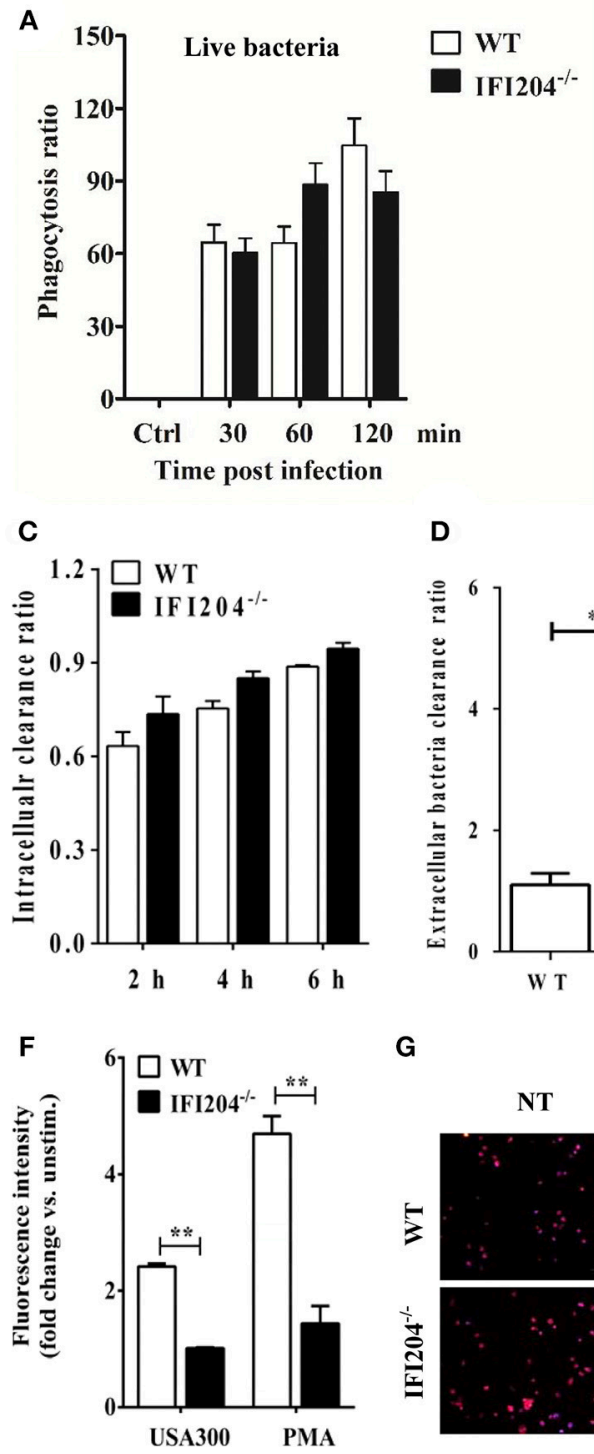

D

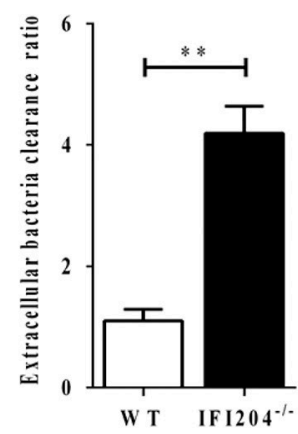

G

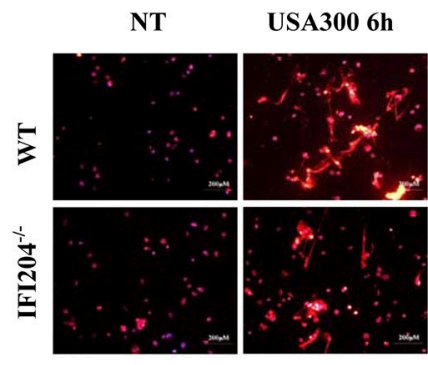

E
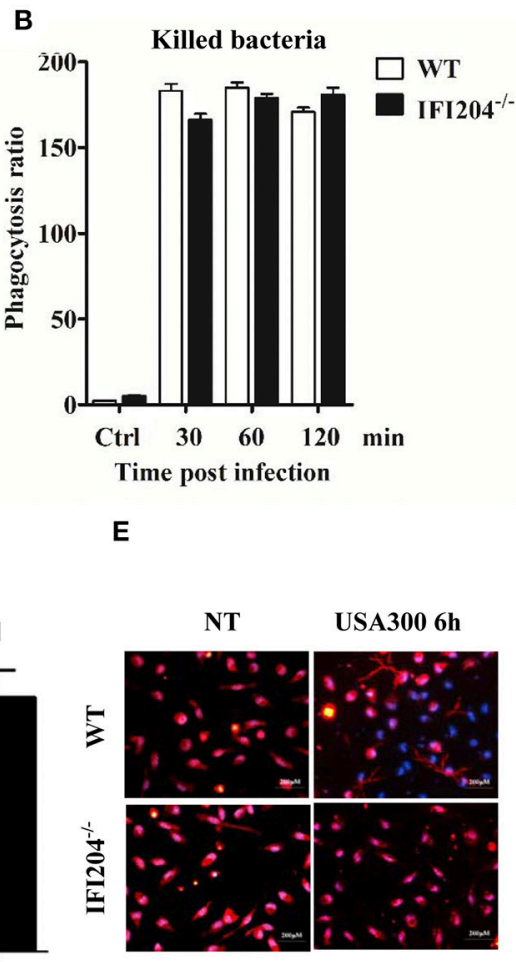

H

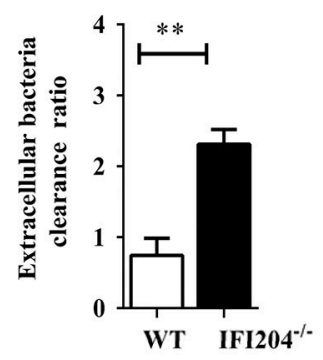

FIGURE 7 | IFI204 promotes extracellular trap-mediated bacteria killing in macrophages and neutrophils. Macrophages were treated with FITC-labeled live (A) or killed bacteria (B). The mean fluorescence intensity (MFI) of the FITC-positive cells were determined by flow cytometry. (C) Macrophages were infected with bacteria $(\mathrm{MOI}=5)$ for $1 \mathrm{~h}$. Non-engulfed bacteria were killed with gentamicin. The cells were lysed and intracellular bacterial were enumerated by plating on agar plates. (D) Extracellular bacterial killing capacity of macrophages were determined by assessing extracellular CFUs. (E) Macrophages were challenged with bacteria (MOI = 50) for 6 h. Representative microscopy pictures of NETs formation as indicated by SYTOX Orange. (F) Macrophages were stimulated with bacteria (MOI = 50) and PMA (100 nM). SYTOX Orange was added after $6 \mathrm{~h}$ and fluorescence was measured by spectrofluorometry. (G) Neutrophils were challenged with bacteria (MOI = 50) for $6 \mathrm{~h}$. Representative microscopy pictures of NETs formation as indicated by SYTOX Orange. (H) Extracellular bacterial killing capacity of neutrophils were determined by assessing extracellular CFUs. All data are shown as mean \pm SEM. Student's $t$-test was performed. ${ }^{\star *} p<0.01$.

is dependent on the ability of IFI204 enhancing phagocyte killing capacity.

\section{DISCUSSION}

Staphylococcus aureus infections are usually persistent and hard to eradicate. Development of new therapeutic strategies to combat Staphylococcus infections requires deeper understanding of molecular mechanisms underlying phagocyte functions in antibacterial defense. Recently, several studies including ours showed that murine IFI204 or human ortholog IFI16 detects cytosolic bacterial DNA for the type I IFN response or cell death in vitro (5-8). Hence, IFI204/IFI16 is implicated in sensing intracellular bacterial infection. Generally speaking, Staphylococcus is extracellular bacteria. Using IFI204-deficient mice, we demonstrate that IFI204 promotes host survival and bacterial clearance during Staphylococcus pulmonary and systemic infection. Therefore, we defining a novel role for IFI204 in host defense against extracellular bacterial infection. 

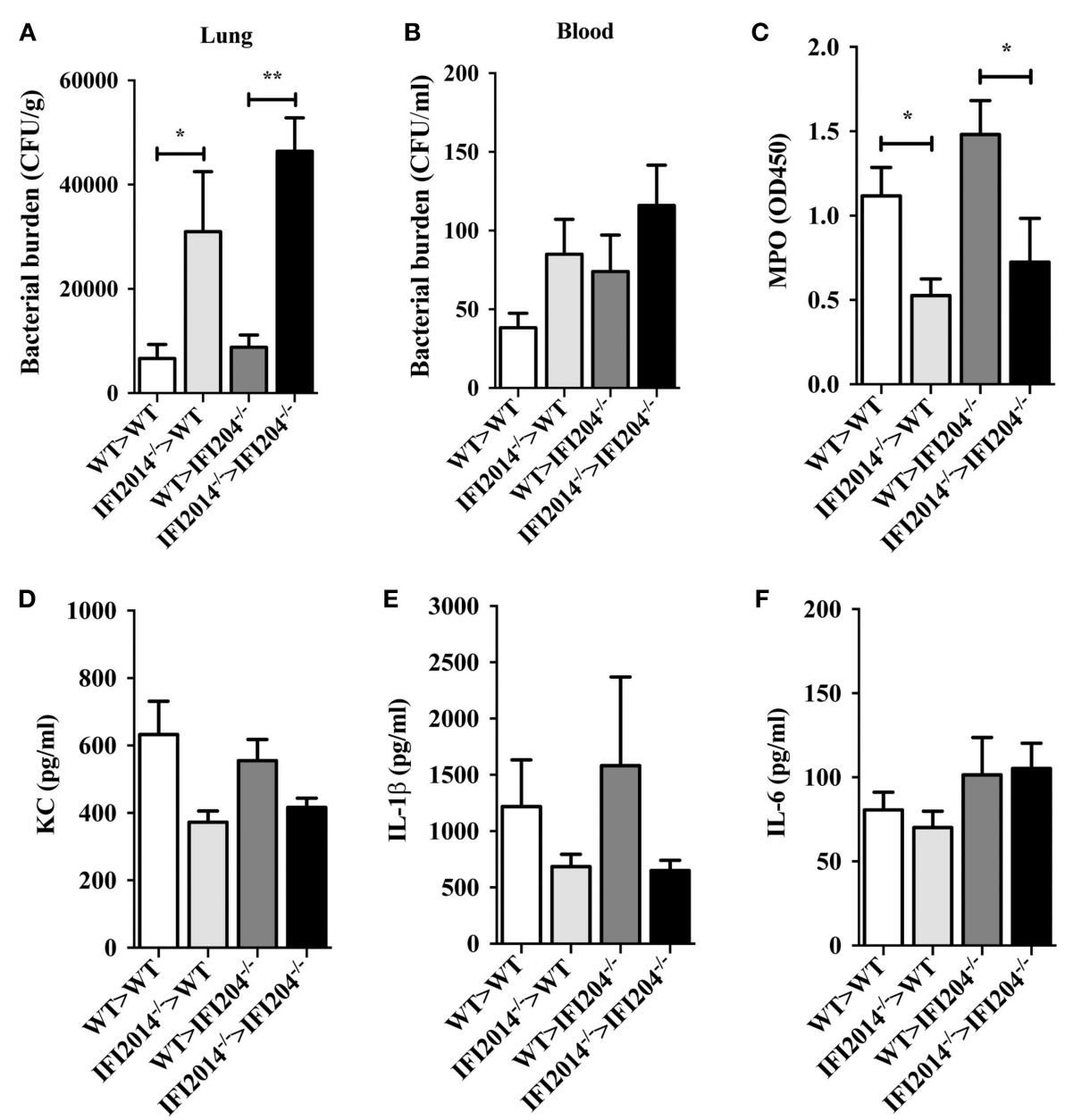

G

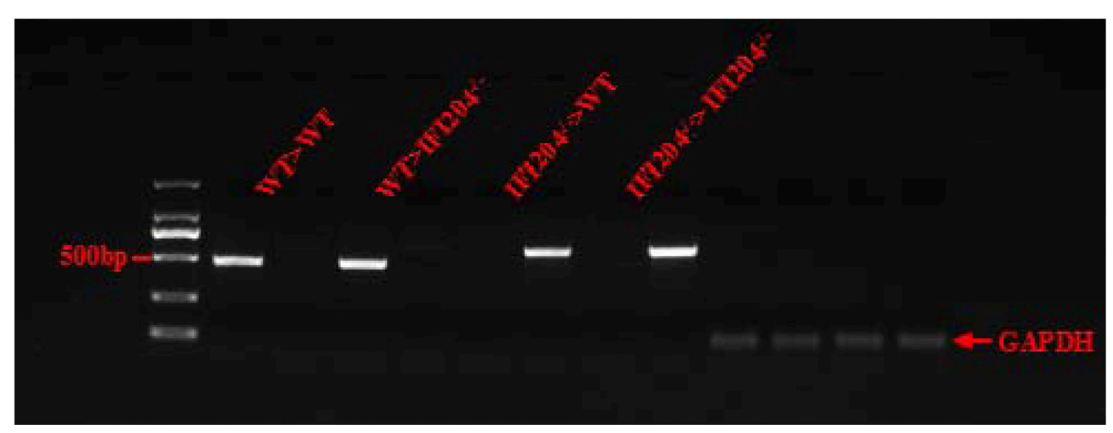

FIGURE 8 | Adoptive transfer of WT BM cells protects IFI204-deficient mice against Staphylococcus infection. Bone marrow cells isolated from WT or IFI204-/- mice were adoptively transferred to irradiated IFI204-/- or WT recipient mice. The recipient mice were then infected nasally with Staphylococcus $\left(1 \times 10^{8}\right.$ CFU, $n=4-6$ each group) for $24 \mathrm{~h}$. (A,B) Homogenized lung tissue and blood were subjected to plating serial dilution for bacterial loads. (C) Neutrophil activity in lung was determined by the amount of MPO. (D-F) The release of KC, IL-6, IL-1 $\beta$ in lung were determined by ELISA. (G) Efficient reconstitution by donor bone marrow cells was confirmed by PCR for the IFI204 gene in splenocytes. All data are shown as mean $\pm \mathrm{SEM}$. Student's $t$-test was performed. ${ }^{*} p<0.05 ;{ }^{* *} p<0.01$.

To identify the potential mechanisms underlined IFI204mediated defense, we set out to characterize the inflammatory response. IFI204 deficiency leads to an inferior production of cytokines/chemokines in the lung following Staphylococcus infection. Due to IFI204 mainly locating in the recruited inflammatory cells, bone marrow-derived macrophages were used for determine IFI204-mediated inflammatory response.
Consistent with in vivo data, IFI204 deficiency not only impairs cytokines production in macrophages, but also inhibits bacteriainduced STING-IRF3 and NF-KB activation. IFI204/IFI16 is extensively characterized as a DNA sensor, which detects cytosolic DNA derived from virus, bacteria, even host DNA (11). In the presence of intracellular DNA, IFI204/IFI16 interacts with STING to induce TBK1-dependent IFN- $\beta$ responses. Using 
Staphylococcus-derived genome DNA, we also showed that cytosolic DNA activates the STING-IRF3 pathway, and promotes IFN- $\beta$ and KC productions. Hence, it is quite possible that IFI204 serve as DNA sensor to trigger inflammatory responses during Staphylococcus infection.

IFN- $\beta$ is produced during viral infections and is responsible for defense against viruses. IFN- $\beta$ also induced by Staphylococcus. However, the role of IFN- $\beta$ during Staphylococcus infection varies. It can be both beneficial $(12,13)$ and detrimental (14-16) to the host, probably depending on the experimental design. We hypothesized that the defect of IFN- $\beta$ production may leads to susceptibility to infection in the absence of IFI204. Unexpectedly, administration of recombinant IFN- $\beta$ even promotes bacteria proliferation in IFI204-deficient mice. Moreover, blockade of IFN signaling significantly decreased the mortality induced by Staphylococcus systemic infection. Hence, it suggests that IFN$\beta$ was not only unnecessary for the protective effects of IFI204, but also detrimental to the host during Staphylococcus infection. Our data also showed that KC production is attenuated in IFI204deficient mice and macrophages. $\mathrm{KC}$ has been shown to have a critical role in protective responses to Staphylococcus infection. However, administration of recombinant mouse $\mathrm{KC}$ is still unable to restrict Staphylococcus multiplication in IFI204-deficient mice.

Phagocytosis, a process by which myeloid cells such as macrophages and neutrophils internalize and kill microorganisms, is the critical host innate defense mechanism. Our results showed that IFI204-deficient macrophages internalized similar numbers of FITC-labeled live or heatkilled bacteria compared with WT macrophages. Moreover, WT and IFI204-deficient macrophages exhibit a comparable capacity for intracellular killing. Because bacterial phagocytosis in IFI204deficient macrophages was not impaired, it is possible that IFI204 participates in the regulation of phagocytosis-independent bacterial killing such as the process mediated by extracellular trap. Extracellular trap was first described in neutrophils as the released of web-like structures after stimulation with Grampositive or Gram-negative bacteria. Increased evidences showed that ET is not formed exclusively by neutrophils but also by other innate myeloid cells including macrophage (17), basophils (18), eosinophil (19), and mast cells (20) response to microbes. Activated innate myeloid cells release these structures composed of decondensed chromatin and antimicrobial proteins that trap and inhibit a broad range of microbes. Compared with control cells, both IFI204-deficient macrophages and neutrophils are incapable of killing extracellular bacteria, as well as reduce the release of extracellular DNA. Moreover, transplantation of WT bone marrow rescued bacterial killing defect in IFI204-deficient mice. Hence, our results indicate that the protective effect of IFI204 against Staphylococcus infection is dependent on the ability of IFI204 enhancing phagocyte killing capacity by promoting ET formation.

Some other pattern recognition receptor including TLR4 (21-23), TLR7/8 (24, 25), TLR2 (23, 26, 27), TLR6 (28),
TLR9 (29), lectin receptors Mincle and CLEC5A (30-32), Fc receptors Fc $\alpha$ RI and Fc $\gamma$ RIIIb $(33,34)$ were implicated in neutrophil extracellular trap formation. TLR2/4 was found to modify NET formation in response to Staphylococcus infection but not to PMA stimulation (23). Interestingly, we observed that IFI204 impact both pathogen and PMAinduced extracellular DNA release. Several virulence factors of Staphylococcus were reported to elicit ET formation, including leukotoxin (35), leukocidins (36), phenol-soluble modulin $\alpha(\mathrm{PSM} \alpha)$ (37), and protein A (38). Given the fact that IFI204 mediates PMA-induced extracellular DNA release, we speculate that IFI204 probably promotes extracellular bactericidal activity independent of DNA recognition. While understanding the underlying mechanism of IFI204 regulating ET awaits further investigation, this study extends our understanding the biological function of IFI204 in host innate immune response.

In summary, our studies demonstrate IFI204 is essential for host defense against Staphylococcus infection in vivo. IFI204 promotes bacteria eradication and inflammation response. However, inflammation response does not contribute to IFI204mediated protection. Moreover, we provide evidence that IFI204 plays a role in extracellular bactericidal activity of phagocytes through enhancing extracellular trap formation. These observations document a novel and physiologically important role for IFI204 in host defense against extracellular bacterial infection.

\section{DATA AVAILABILITY}

All datasets generated for this study are included in the manuscript and/or the supplementary files.

\section{ETHICS STATEMENT}

All animal studies were conducted according to experimental practices and standards approved by the Animal Welfare and Research Ethics Committee at Jilin University (No. 20150601).

\section{AUTHOR CONTRIBUTIONS}

WC and Y-JY: designed experiments. WC, S-XY, F-HZ, and X-JZ: performed the experiments. WC and S-XY: analyzed the data. Y-JY: wrote the manuscript. W-YG, K-YL, Z-ZL, and W-YH: read the manuscript.

\section{FUNDING}

This work was supported by The National Key Research and Development Program of China [No. 2017YFD0501000], National Natural Science Foundation of China [No. 31872457, No. 31702211], Jilin Province Science and Technology Development Project [No. 20160101232JC]. 


\section{REFERENCES}

1. Kaufmann SHE, Dorhoi A. Molecular determinants in phagocyte-bacteria interactions. Immunity. (2016) 44:476-91. doi: 10.1016/j.immuni.2016. 02.014

2. Unterholzner L, Keating SE, Baran M, Horan KA, Jensen SB, Sharma S, et al. IFI16 is an innate immune sensor for intracellular DNA. Nat Immunol. (2010) 11:997-1004. doi: 10.1038/ni.1932

3. Monroe KM, Yang Z, Johnson JR, Geng X, Doitsh G, Krogan NJ, et al. IFI16 DNA sensor is required for death of lymphoid CD4 T cells abortively infected with HIV. Science. (2014) 343:428-32. doi: 10.1126/science.12 43640

4. Jakobsen MR, Bak RO, Andersen A, Berg RK, Jensen SB, Tengchuan J, et al. IFI16 senses DNA forms of the lentiviral replication cycle and controls HIV-1 replication. Proc Natl Acad Sci USA. (2013) 110:E4571-80. doi: $10.1073 /$ pnas. 1311669110

5. Storek KM, Gertsvolf NA, Ohlson MB, Monack DM. cGAS and Ifi204 cooperate to produce type I IFNs in response to Francisella infection. J Immunol. (2015) 194:3236-45. doi: 10.4049/jimmunol.14 02764

6. Hansen K, Prabakaran T, Laustsen A, Jorgensen SE, Rahbaek SH, Jensen $\mathrm{SB}$, et al. Listeria monocytogenes induces IFNbeta expression through an IFI16-, cGAS- and STING-dependent pathway. EMBO J. (2014) 33:1654-66. doi: 10.15252/embj.201488029

7. Chunfa L, Xin S, Qiang L, Sreevatsan S, Yang L, Zhao D, et al. The central role of IFI204 in IFN-beta release and autophagy activation during Mycobacterium bovis infection. Front Cell Infect Microbiol. (2017) 7:169. doi: $10.3389 /$ fcimb. 2017.00169

8. Chu X, Chen W, Li N, Hu XZ, Du CT, Yu SX, et al. Cytosolic double-stranded DNA induces non-necroptotic programmed cell death in trophoblasts via IFI16. J Infect Dis. (2014) 210:1476-86. doi: 10.1093/infdis/j iu272

9. Barber GN. STING-dependent cytosolic DNA sensing pathways. Trends Immunol. (2014) 35:88-93. doi: 10.1016/j.it.2013. 10.010

10. Metzler KD, Fuchs TA, Nauseef WM, Reumaux D, Roesler J, Schulze I, et al. Myeloperoxidase is required for neutrophil extracellular trap formation: implications for innate immunity. Blood. (2011) 117:953-9. doi: 10.1182/blood-2010-06-290171

11. Ma Z, Ni G, Damania B. Innate sensing of DNA virus genomes. Annu Rev Virol. (2018) 5:341-62. doi: 10.1146/annurev-virology-092917-043244

12. Kaplan MJ, Kyme P, Wolf AJ, Becker CA, Tseng CW, Liu GY, et al. Failure to induce IFN-beta production during Staphylococcus aureus infection contributes to pathogenicity. J Immunol. (2012) 189:4537-45. doi: 10.4049/jimmunol.1201111

13. Kaplan A, Lee MW, Wolf AJ, Limon JJ, Becker CA, Ding M, et al. Direct antimicrobial activity of IFN-beta. J Immunol. (2017) 198:4036-45. doi: 10.4049/jimmunol.1601226

14. Martin FJ, Gomez MI, Wetzel DM, Memmi G, O’Seaghdha M, Soong G, et al. Staphylococcus aureus activates type I IFN signaling in mice and humans through the Xr repeated sequences of protein A. J Clin Invest. (2009) 119:1931-9. doi: 10.1172/JCI35879

15. Parker D, Planet PJ, Soong G, Narechania A, Prince A. Induction of type I interferon signaling determines the relative pathogenicity of Staphylococcus aureus strains. PLoS Pathog. (2014) 10:e1003951. doi: 10.1371/journal.ppat.1003951

16. Parker D, Prince A. Staphylococcus aureus induces type I IFN signaling in dendritic cells via TLR9. J Immunol. (2012) 189:4040-6. doi: 10.4049/jimmunol.1201055

17. Chow OA, von Kockritz-Blickwede M, Bright AT, Hensler ME, Zinkernagel AS, Cogen AL, et al. Statins enhance formation of phagocyte extracellular traps. Cell Host Microbe. (2010) 8:445-54. doi: 10.1016/j.chom.2010. 10.005

18. Morshed M, Hlushchuk R, Simon D, Walls AF, Obata-Ninomiya K, Karasuyama $\mathrm{H}$, et al. NADPH oxidase-independent formation of extracellular DNA traps by basophils. J Immunol. (2014) 192:5314-23. doi: 10.4049/jimmunol.1303418
19. Yousefi S, Gold JA, Andina N, Lee JJ, Kelly AM, Kozlowski E, et al. Catapult-like release of mitochondrial DNA by eosinophils contributes to antibacterial defense. Nat Med. (2008) 14:949-53. doi: 10.1038/n m.1855

20. von Kockritz-Blickwede M, Goldmann O, Thulin P, Heinemann K, NorrbyTeglund A, Rohde M, et al. Phagocytosis-independent antimicrobial activity of mast cells by means of extracellular trap formation. Blood. (2008) 111:307080. doi: 10.1182/blood-2007-07-104018

21. Clark SR, Ma AC, Tavener SA, McDonald B, Goodarzi Z, Kelly MM, et al. Platelet TLR4 activates neutrophil extracellular traps to ensnare bacteria in septic blood. Nat Med. (2007) 13:463-9. doi: 10.1038/n m1565

22. Yousefi S, Mihalache C, Kozlowski E, Schmid I, Simon HU. Viable neutrophils release mitochondrial DNA to form neutrophil extracellular traps. Cell Death Differ. (2009) 16:1438-44. doi: 10.1038/cdd.2 009.96

23. Wan T, Zhao Y, Fan F, Hu R, Jin X. Dexamethasone inhibits S. aureusinduced neutrophil extracellular pathogen-killing mechanism, possibly through toll-like receptor regulation. Front Immunol. (2017) 8:60. doi: 10.3389/fimmu.2017.00060

24. Saitoh T, Komano J, Saitoh Y, Misawa T, Takahama M, Kozaki T, et al. Neutrophil extracellular traps mediate a host defense response to human immunodeficiency virus-1. Cell Host Microbe. (2012) 12:109-16. doi: 10.1016/j.chom.2012.05.015

25. Lood C, Arve S, Ledbetter J, Elkon KB. TLR7/8 activation in neutrophils impairs immune complex phagocytosis through shedding of FcgRIIA. J Exp Med. (2017) 214:2103-19. doi: 10.1084/jem.201 61512

26. Yipp G, Petri B, Salina D, Jenne CN, Scott BN, Zbytnuik LD, et al. Infection-induced NETosis is a dynamic process involving neutrophil multitasking in vivo. Nat Med. (2012) 18:1386-93. doi: 10.1038/n m.2847

27. Xu F, Zhang C, Zou Z, Fan EK Y, Chen L, Li Y, et al. Aging-related Atg5 defect impairs neutrophil extracellular traps formation. Immunology. (2017) 151:417-32. doi: 10.1111/imm.12740

28. Awasthi D, Nagarkoti S, Kumar A, Dubey M, Singh AK, Pathak P, et al. Oxidized LDL induced extracellular trap formation in human neutrophils via TLR-PKC-IRAK-MAPK and NADPH-oxidase activation. Free Radic Biol Med. (2016) 93:190-203. doi: 10.1016/j.freeradbiomed.2016. 01.004

29. Itagaki K, Kaczmarek E, Lee YT, Tang IT, Isal B, Adibnia Y, et al. Mitochondrial DNA released by trauma induces neutrophil extracellular traps. PLoS ONE. (2015) 10:e0120549. doi: 10.1371/journal.pone.0120549

30. Sharma A, Steichen AL, Jondle CN, Mishra BB, Sharma J. Protective role of Mincle in bacterial pneumonia by regulation of neutrophil mediated phagocytosis and extracellular trap formation. J Infect Dis. (2014) 209:183746. doi: 10.1093/infdis/jit820

31. Sharma A, Simonson TJ, Jondle CN, Mishra BB, Sharma J. Mincle-mediated neutrophil extracellular trap formation by regulation of autophagy. $J$ Infect Dis. (2017) 215:1040-8. doi: 10.1093/infdis/jix072

32. Chen ST, Li FJ, Hsu TY, Liang SM, Yeh YC, Liao WY, et al. CLEC5A is a critical receptor in innate immunity against Listeria infection. Nat Commun. 8:299. doi: 10.1038/s41467-017-00356-3

33. Aleyd E, van Hout MW, Ganzevles SH, Hoeben KA, Everts V, Bakema JE, et al. IgA enhances NETosis and release of neutrophil extracellular traps by polymorphonuclear cells via Fcalpha receptor. J Immunol. (2014) 192:237483. doi: 10.4049/jimmunol.1300261

34. Aleman OR, Mora N, Cortes-Vieyra R, Uribe-Querol E, Rosales C. Differential use of human neutrophil fcgamma receptors for inducing neutrophil extracellular trap formation. J Immunol Res. (2016) 2016:2908034. doi: $10.1155 / 2016 / 2908034$

35. Malachowa N, Kobayashi SD, Freedman B, Dorward DW, DeLeo FR. Staphylococcus aureus leukotoxin GH promotes formation of neutrophil extracellular traps. J Immunol. (2013) 191:6022-9. doi: 10.4049/jimmunol.1301821

36. Bhattacharya M, Berends ET, Chan R, Schwab E, Roy S, Sen CK, et al. Staphylococcus aureus biofilms release leukocidins to elicit extracellular trap 
formation and evade neutrophil-mediated killing. Proc Natl Acad Sci USA. (2018) 115:7416-21. doi: 10.1073/pnas.1721949115

37. Bjornsdottir H, Dahlstrand Rudin A, Klose FP, Elmwall J, Welin A, Stylianou M, et al. Phenol-soluble modulin alpha peptide toxins from aggressive staphylococcus aureus induce rapid formation of neutrophil extracellular traps through a reactive oxygen species-independent pathway. Front Immunol. (2017) 8:257. doi: 10.3389/fimmu.2017.00257

38. Hoppenbrouwers T, Sultan AR, Abraham TE, Lemmens-den Toom NA, Hansenova Manaskova S, van Cappellen WA, et al. Staphylococcal protein a is a key factor in neutrophil extracellular traps formation. Front Immunol. 9:165. (2018) doi: 10.3389/fimmu.2018.00165
Conflict of Interest Statement: The authors declare that the research was conducted in the absence of any commercial or financial relationships that could be construed as a potential conflict of interest.

Copyright $\odot 2019$ Chen, Yu, Zhou, Zhang, Gao, Li, Liu, Han and Yang. This is an open-access article distributed under the terms of the Creative Commons Attribution License (CC BY). The use, distribution or reproduction in other forums is permitted, provided the original author(s) and the copyright owner(s) are credited and that the original publication in this journal is cited, in accordance with accepted academic practice. No use, distribution or reproduction is permitted which does not comply with these terms. 